
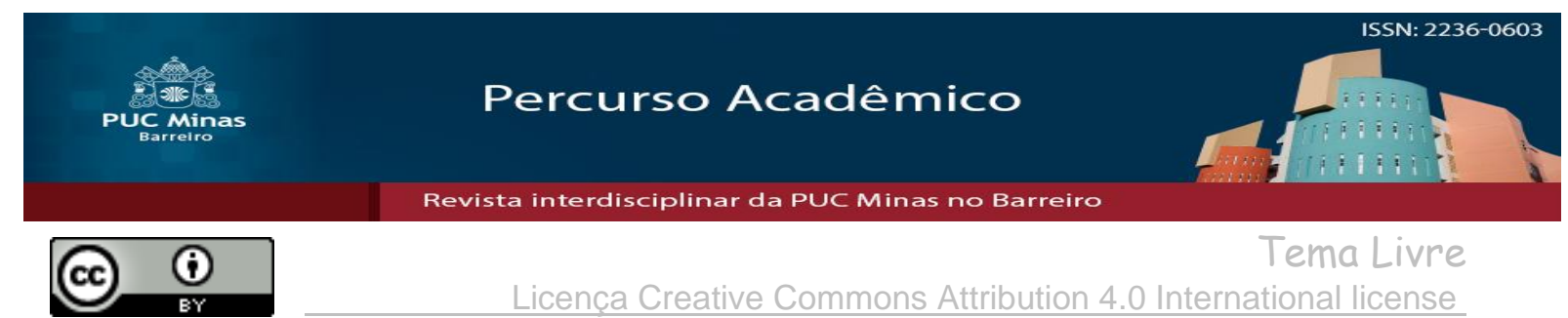

Tema Livre Licença Creative Commons Attribution 4.0 International license

\title{
TÓPICA E INDUÇÃO: os limites do raciocínio indutivo pautados em formalismos lógicos no âmbito da técnica do pensamento problemático proposta por Theodor Viehweg
}

TOPIC AND INDUCTION: the limits of inductive reasoning based on logical formalisms within the problematic thinking technique proposed by Theodor Viehweg

Sidney Geraldo Cota de Assis ${ }^{1}$

\begin{abstract}
RESUMO
Esta pesquisa aborda os limites do raciocínio indutivo pautados em formalismos lógicos no âmbito da Tópica Jurídica proposta por Theodor Viehweg. Os objetivos traçados dizem respeito a) à demonstração do caráter defectivo da indução por se tratar de um processo de inferência qualificado pelo juízo de probabilidade ou verossimilhança das suas conclusões em que se compreende a natureza do discurso dialético aristotélico contrário ao modus apodíctico; b) à confirmação de que a Tópica Jurídica concebida como técnica do pensamento problemático em Theodor Viehweg é essencialmente indutiva e, por isso, apresenta um aspecto falho. A metodologia utilizada para tanto é a revisão/pesquisa bibliográfica cujos autores e teorias elencados são discutidos a partir do método implicativo lógico próprio do tipo dissertativoargumentativo textual. Ao fim, conclui-se que a argumentação jurídica de cunho tópico, do ponto de vista da lógica, não pode ser justificada ao modo dedutivo, pois há de se considerar a dúvida se o foco for a

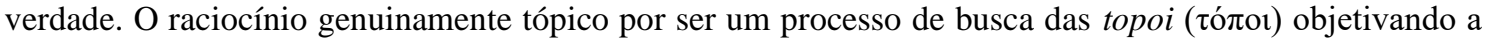
solução de aporias não se atém à verdade ou demonstrabilidade das premissas com as quais trata, mas as aceita como possivelmente aptas a solucionarem o problema em debate. Neste sentido, a Tópica por ser substancialmente indutiva está vinculada ao caráter defeituoso deste tipo de raciocínio sem que por isso seja inviabilizada e afastada totalmente do campo do Direito, mas apenas de algumas áreas.
\end{abstract}

\section{Palavras-chave: Tópica. Raciocínio indutivo. Lógica. Argumentação jurídica.}

\begin{abstract}
This research treats about the limits of inductive reasoning based on logical formalisms in the Legal Topic proposed by Theodor Viehweg. The main objectives concern in a) the demonstration of the defective character of induction as a process of inference qualified by the probability or verisimilitude judgment of its conclusions in where is the nature of the Aristotelian dialectic discourse contrary to the apodictic modus; b) the confirmation that the Legal Topic conceived as a technique of problematic thinking in Theodor Viehweg is essentially inductive so it presents a flawed aspect. The methodology used for this is the bibliographic review/research whose authors and listed theories are discussed from the logical implicative method of the textual dissertative-argumentative kind. At the end, it is concluded that the legal argument of a topical nature, from the point of view of logic, cannot be justified in a deductive way, as it is necessary to consider the doubt if the focus is on the truth. Genuinely topical reasoning, as it is a process of searching for topoi ( $\tau$ ó $\pi 01)$ aiming at solving aporias, does not limit itself to the truth or demonstrability of the premises it deals with, but accepts them as possibly capable of solving the problem under discussion. In this sense, the Topic, for being substantially inductive, is linked to the defective character of this reasoning without being unfeasible and completely alienate from Law, but only in a few areas.
\end{abstract}

Keywords: Topic.Iinductive reasoning. Logic. Legal reasoning.

Artigo enviado em 23 de outubro de 2021 e aprovado em 08 de novembro 2021

${ }^{1}$ Graduado em Direito e especialização em Direito Processual Civil pela Pontifícia Universidade

Católica de Minas Gerais, Brasil. E-mail: sidney_gca@hotmail 


\section{INTRODUÇÃO}

O problema que motiva e ao mesmo tempo norteia esta pesquisa diz respeito aos limites da indução pautados em formalismos lógicos dimensionados na perspectiva da Tópica Jurídica proposta por Theodor Viehweg.

Pretende-se demonstrar que a teoria da argumentação jurídica definida como Tópica nos termos metodológicos de Viehweg é essencialmente indutiva e, dessa forma, sujeita-se ao caráter defectivo desse tipo de raciocínio lógico.

Os objetivos principais, nessa ótica, perpassam pela delimitação conceitual da indução, compreendendo-se os aspectos do argumento por analogia, das relações causais no âmbito do raciocínio por generalização e, por fim, os limites do problema da indução apontado por POPPER (1999), tudo conforme disposto no Capítulo 2.

Na sequência, o escopo do estudo será voltado para a conceituação da Tópica ou técnica do pensamento problemático (VIEHWEG, 1979) a partir do seu caráter primordialmente indutivo. Ao fim, determinar-se-á um contraponto entre Tópica e Indução, de acordo com o Capítulo 3.

\section{INDUÇÃO}

Entende-se, nos limites desta explanação, por raciocínio indutivo o mesmo que argumento indutivo, ou inferências indutivas, ou método indutivo, ou simplesmente indução. O que é, portanto, indução?

Responder a esta pergunta requer demasiado esforço teórico-bibliográfico que não seria compatível aos moldes desta pesquisa. Por uma breve pretensão de dimensionar a questão, vale citar:

Desde Bacon até o século XIX destacaram-se as seguintes concepções da indução:

(A) Concepções baseadas nas idéias (sic) baconianas, adotadas por alguns autores de tendência empirista.

(B) Concepções fundamentadas nas idéias (sic) aristotélicas, adotadas pela maioria dos autores escolásticos e por outros de tendência realista moderada e conceitualista.

(C) Concepções que insistiram numa noção "positiva" da indução, quase equivalente à idéia (sic) platônica de "ascensão" da mente dos particulares aos princípios, adotadas por vários racionalistas, em especial por Leibniz.

(D) Concepções segundo as quais o raciocínio indutivo baseia-se no hábito gerado pela observação de que certos acontecimentos se seguem normalmente a outros, de modo que pode predizer-se que isso continuará acontecendo no futuro. O originador dessas teorias foi Hume. 
(E) Concepções segundo as quais os juízos indutivos - ou, melhor, a justificação de tais juízos - se explicam pela estrutura da consciência transcendental. O pai dessa concepção foi Kant.

Durante o século XIX, destacaram-se várias teorias da indução. John Stuart Mill desenvolveu um sistema de lógica indutiva, do qual um dos resultados mais importantes e conhecidos são os cânones de indução. Idéias (sic) importantes sobre a indução são devidas a Peirce e a Lachelier.

As doutrinas sobre a indução e o raciocínio indutivo - sobretudo a respeito do raciocínio indutivo como raciocínio provável - proliferaram no século atual. Indicamos alguns dos autores que se ocuparam do problema da indução a partir de pontos de vista muito diversos: R. Carnap, N. Goodman, C. G. Hempel, J. M. Keynes, J. Nicod, C. S. Peirce, K. R. Popper, H. Reichenbach, R. von Mises e G. H. von Wright. (MORA, 2001, p. 382-383).

A resposta que se pretende é menos pretenciosa. Delinear-se-á os limites semânticos da indução na perspectiva da dialética aristotélica.

Vale dizer como abaixo:

A dialética é para Aristóteles uma forma não demonstrativa de conhecimento: é uma "aparência de filosofia", mas não a própria filosofia. Daí que Aristóteles seja propenso a considerar num mesmo nível discussão, probabilidade e dialética. A dialética, diz Aristóteles, é discussão e não ciência; probabilidade e não certeza; "indução" e não propriamente "demonstração". E sucede até que a dialética é tomada por Aristóteles num sentido pejorativo, não só como um saber do meramente provável, mas também como um "saber" (que é, com certeza, um "pseudo-saber") do aparentemente tomado como real. Por isso, Aristóteles chega a chamar "dialético" ao silogismo "erístico", no qual as premissas não são sequer prováveis, apenas parecem sê-lo. (MORA, 2001, p. 183-184, grifos nossos).

A dialética em Aristóteles, portanto, denota um juízo de probabilidade. Com isso, o conceito de indução adotado nesta pesquisa será precisamente o que diz respeito a um processo argumentativo, ou de raciocínio, cuja inferência resulte numa conclusão provavelmente verdadeira, sem, contudo, haver de ser certa ou provada.

Tal arcabouço teórica se baseia no entendimento adotado por IRVING COPI (1978), o qual suscitará o bojo da explanação que se seguirá acerca do tema, também a tese resolutiva do problema da indução proposta por POPPER (1999), conforme se subseguirá. 


\subsection{Argumento por analogia}

Dentre os tipos de raciocínio indutivo, destaca-se o argumento por analogia em razão de ser rotineiramente empregado nos mais variados contextos locucionais. Não raro, o ser humano, diante da incerteza quanto ao futuro, busca pautar sua forma de pensar e agir a partir das suas experiências pretéritas.

O argumento analógico não se classifica como válido ou inválido tal qual ocorre no raciocínio dedutivo, mas tão somente como muito provável, ou pouco provável, de acordo com COPI (1978), filósofo, lógico e professor universitário estadunidense. Vale referenciar: "traçar uma analogia entre duas ou mais entidades é indicar um ou mais aspectos em que elas são semelhantes.” (COPI, 1978, p. 315).

Em suma, o uso argumentativo da analogia se caracteriza na determinação de que algumas coisas possuem certos aspectos, sendo uma ou mais dessas coisas destituídas de ao menos um dos aspectos comuns às demais, mas, data a coincidência desses aspectos em relação à maioria das coisas, trona-se possível conjecturar que essa coisa destituída de algum dos aspectos poderia ter esse aspecto faltante.

Nesse ponto, cabe inquirir: afinal, por que então respaldar uma conclusão cujo raciocínio constituinte se vale do uso argumentativo da analogia? Porque diante da dúvida da conclusão e da impossibilidade de constatar a verdade das premissas, pressupondo ser pretensão primeira o convencimento, a probabilidade da conclusão é capaz de surtir considerável efeito persuasivo na perspectiva do colocutor. Trata-se de uma funcionalidade retórica.

\subsection{O argumento por generalização no âmbito das relações causais}

Os fenômenos observáveis, aquilo que existe fora do homem, no meio em que o circunda, em sua maioria, podem ser explicados a partir das conexões causais. Noutros termos mais precisos, para que se exerça algum conhecimento objetivo acerca da natureza, é indispensável apreender o conceito de causa e efeito (COPI, 1978).

Todo evento ocorre sob certas condições. Eis um axioma fundamental das ciências naturais. Essas condições podem ser necessárias ou suficientes (COPI, 1978).

Uma condição necessária é "circunstância em cuja ausência o evento não possa ocorrer." (COPI, 1978, p. 329). 
Uma condição suficiente é "circunstância em cuja presença o evento deve ocorrer." (COPI, 1978, p. 329).

O termo causa, portanto, pode ser utilizado tanto no sentido de condição necessária, quanto no sentido de condição suficiente.

Dentre todos os significados possíveis de causa (HOUAISS, 2009, p. 456), para a presente pesquisa, importa o conceito de que "causa é uma condição necessária e suficiente para o seu efeito". (COPI, 1978, p. 331).

Tal delimitação conceitual de causa, segundo COPI (1978), requer admitir a teoria da Unicidade de Causas em detrimento da teoria da Pluralidade de Causas.

A teoria da Causa Única permite constatar inúmeros fatores como condição para a ocorrência de dado efeito sem, contudo, caracterizar uma pluralidade de causas, mas tão somente um complexo causal que torna essa multiplicidade apenas aparente.

A tese da Pluralidade de Causas é incompatível com causa enquanto condição necessária e suficiente para um efeito. Nesse sentido, cita-se:

A noção de que pode haver uma "pluralidade de causas" de uma única espécie de efeito choca-se com a noção de que uma causa é uma condição necessária e suficiente para o seu efeito. Se pode haver uma pluralidade de causas, então, as inferências dos efeitos para as suas causas são impossíveis. (COPI, 1978, p. $331)$.

A causa e o efeito estão uniformemente ligados (COPI, 1978) e implicados com uma lei causal geral definida como "uma asserção, segundo a qual uma certa circunstância está invariavelmente acompanhada por tal e tal fenômeno, quando e onde quer que se produza.” (COPI, 1978, p. 333).

Afirmar que o sentido de causa utilizado até então diz respeito a uma parcela da lei causal geral significa que como uma circunstância particular gera um efeito específico, então em qualquer outra situação nas mesmas circunstâncias sempre ocorrerá o mesmo efeito.

A noção de causa como correlata da lei causal geral indica assertivas que possuem um grau de generalidade. A relação causal não é dedutiva ou demonstrada por um raciocínio a priori. As leis causais são demonstradas apenas empiricamente, ou seja, através da experimentação ou observação que o sujeito faz do fenômeno (COPI, 1978).

Diante disso, cabe a seguinte questão: observadas várias ocorrências da circunstância $\mathrm{C}$ em que cada qual resulta no fenômeno $\mathrm{F}$, é possível afirmar que alguns 
casos de C acarretam F. Entretanto, como a partir dessas observações específicas seria possível afirmar que todo $\mathrm{C}$ causa $\mathrm{F}$ ?

Em reposta, propõe-se a generalização indutiva (COPI, 1978) como método de procedência de uma relação causal particularmente concebida e implicada com uma lei causal geral enquanto parcela desta, isto é, da possibilidade de se afirmar uma proposição universal a partir de fatos particulares da experiência.

Nota-se que a diferença entre o argumento analógico do argumento indutivo por generalização diz respeito tão somente à conclusão universal deste em comparação à conclusão particular daquele. Assim, a generalização indutiva tal qual exposta é denominada indução por simples enumeração (COPI, 1978).

\title{
1.3 O problema filosófico tradicional da indução reformulado e solucionado por
}

\section{Karl Popper - a Teoria da Falseabilidade}

As afirmações feitas anteriormente sobre a indução pretenderam torná-la conceitualmente apreensível. Doravante, por meio do "discurso crítico", "racional", "lógico" e “objetivo" ao modo de POPPER (1999), demonstrar-se-á que o método indutivo tanto em sua própria concepção, quanto em sua aplicabilidade é, nada além, senão que defectivo.

Popper denominou de problema filosófico tradicional da indução a indagação seguinte: "qual é a justificativa para a crença de que o futuro será (amplamente) como o passado? Ou, talvez, qual é a justificativa para as inferências indutivas?” (POPPER, 1999, p. 14).

E acrescentou:

\begin{abstract}
Formulações como estas estão erroneamente feitas, por várias razões. Por exemplo, a primeira supõe que o futuro será como o passado, suposição que, de início, considero errada, a menos que a palavra "como" seja tomada em sentido tão flexível que torne a suposição vazia e inócua. A segunda formulação supõe que há inferências indutivas e normas para extrair inferências indutivas e esta, mais uma vez, é uma suposição que não deveria ser feita sem crítica e que também considero errada. (POPPER, 1999, p. 14).
\end{abstract}

Essa formulação, segundo POPPER (1999), decorre da crítica filosófica elaborada por David Hume à indução no sentido de perscrutar se as crenças humanas poderiam ser justificadas ou fundamentadas. 
Diante disso, na pretensão de formular o problema que julgou estar implícito ao problema tradicional da indução, Popper extraiu de Hume a questão seguinte: "somos justificados em raciocinar partindo de exemplos (repetidos), dos quais temos experiência, para outros exemplos (conclusões), dos quais não temos experiência?” (POPPER, 1999, p. 15).

Reescrito de forma objetiva ou lógica ao modo de POPPER (1999), onde se lê "exemplos de que temos experiência", leia-se "asserções de teste"; onde se lê "exemplos de que não temos experiência", leia-se "teorias explanativas universais".

Assim, o problema da indução concebido por Popper compreende o seguinte:

$\mathrm{L}_{1}$ - pode a alegação de que uma teoria explanativa universal é verdadeira se justificada por "razões empíricas"; isto admitindo a verdade de certas asserções de teste ou asserções de observação (que, pode-se dizer, são "baseadas em experiência”)? (POPPER, 1999, p. 18).

Ao que responde: "minha resposta ao problema é a mesma de Hume: Não, não pode. Nenhuma quantidade de asserções de teste verdadeiras justificaria a alegação de que uma teoria explanativa universal é verdadeira.” (POPPER, 1999, p. 18).

Afirmar a verdade de uma proposição universal justificada a partir de uma proposição particular é ilógico.

Se se dissesse:

Esses feijões são daquela saca.

Esses feijões são brancos.

Logo, todos os feijões daquela saca são brancos.

Não haveria, do que se concluiu, qualquer respaldo lógico. Esse argumento bem ilustra tal invalidade lógica.

Um argumento silogístico possui validade lógica quando se observam três princípios, quais sejam: a) non distributivo medii (necessária distribuição do termo médio); b) ordem de afirmações e negações das premissas; c) distribuição dos termos maiores e menores.

O Princípio da distribuição do termo médio diz respeito às formas em que os termos ocorrem nas proposições (termos Sujeito e Predicado). 
Segundo COPI (1978), diz-se que um termo está distribuído caso haja referência a todos os membros da classe designada pelo termo (sujeito ou predicado). Dito de outra forma, caso o termo seja direcionado a todos os membros da classe à qual se vincula, então admite-se que esse termo está distribuído. Por exemplo, na assertiva todos os deputados são cidadãos, pode-se afirmar que todo e qualquer deputado (ou seja, todos os membros da classe dos deputados) estão incluídos na classe dos cidadãos, mas por outro lado, não se pode afirmar que todos os membros da classe dos cidadãos estão incluídos na classe dos deputados. Assim, somente o termo sujeito está distribuído.

Pelo Princípio da ordem de afirmações e negações das premissas, se as premissas forem constituídas de proposições negativas e a conclusão for afirmativa, então cometese a falácia das premissas exclusivas (COPI, 1978) e, portanto, o raciocínio é incorreto. Veja-se:

\begin{tabular}{|l|l|l|l|l|}
\hline $\mathbf{1}^{\mathbf{a}}$ premissa - proposição & Afirmativa & $\begin{array}{l}\text { Afirmativ } \\
\mathbf{a}\end{array}$ & Negativa & Negativa \\
\hline $\mathbf{2}^{\mathbf{a}}$ premissa - proposição & Afirmativa & Negativa & Afirmativa & Negativa \\
\hline Conclusão - proposição & Afirmativa & Negativa & Negativa & Afirmativa (Inválido) \\
\hline
\end{tabular}

As proposições afirmativas indicam que uma classe (sujeito) está contida na outra (predicado), seja totalmente, seja parcialmente. Isso significa que há uma relação de inclusão entre as classes. Já as proposições negativas afirmas somente que uma classe (sujeito e predicado) está totalmente ou parcialmente excluída da outra. Assim, se nas premissas não for delineada tal relação, a conclusão não poderá propor que uma classe esteja contida no todo ou em parte na outra. É inviável relacionar as classes das premissas por meio de uma conclusão afirmativa já que elas não possuem qualquer interseção.

Pelo Princípio da distribuição dos termos maiores e menores, deve haver uma relação determinada de distribuição do termo maior e do termo menor nas premissas em comparação com a conclusão na seguinte ordem:

\begin{tabular}{|lll|l|l|l|l|}
\hline $\begin{array}{l}\text { Termo Maior/Termo } \\
\text { premissas }\end{array}$ & Menor das & Distribuído & Distribuído & $\begin{array}{l}\text { Não } \\
\text { Distribuído }\end{array}$ & $\begin{array}{l}\text { Não } \\
\text { Distribuído }\end{array}$ \\
\hline $\begin{array}{l}\text { Termo Menor/Termo } \\
\text { conclusão }\end{array}$ & Maior da & Distribuído & Não Distribuído & Distribuído & $\begin{array}{l}\text { Não } \\
\text { Distribuído }\end{array}$ \\
\hline Validade lógica & & Válido & Válido & Inválido & Válido \\
\hline
\end{tabular}


A conclusão não pode informar além do que as próprias premissas das quais derivou informa. Portanto, se nas premissas os termos não estiverem distribuídos, na conclusão não caberá distribuí-lo, sob pena de se incorrer no ilícito maior ou ilícito menor (COPI, 1978).

No silogismo exemplificativo acima em que as premissas são constituídas por proposições particulares e a conclusão por uma proposição universal, ocorre a violação ao princípio da necessária distribuição do termo médio. Evidente é, neste caso, que o conectivo esses feijões (termo médio) não está distribuído, haja vista se referir apenas a uma porção do conjunto feijão e não a sua totalidade. Como, dessa forma, justificar a conclusão que menciona a inteireza do grupo feijão se deste nada se afirmar em sentido amplo?

Disso decorre que nenhuma teoria explanativa universal (proposição universal, ou teoria científica, ou lei empírica universal) pode se justificar como verdadeira com base em asserções de teste (ou proposições particulares, ou asserções de observação, ou asserções básicas).

Assim, acrescenta POPPER (1999), na sua reformulação do problema da indução, um segundo questionamento que, segundo ele, trata-se de uma generalização de $\mathrm{L}_{1}$ :

$\mathrm{L}_{2}$ - Pode a alegação de que uma teoria explanativa universal é verdadeira, ou é falsa, ser justificada por "razões empíricas"; isto é, pode a admissão da verdade de asserções de teste justificar a alegação de que uma teoria universal é verdadeira, ou a alegação de que é falsa? (POPPER, 1999, p. 18).

Em resposta afirma: “a este problema, minha resposta é positiva: sim, a admissão da verdade de asserções de teste às vezes nos permite justificar a alegação de que uma teoria explanativa universal é falsa." (POPPER, 1999, p. 18).

Pode-se recorrer a duas explicações lógicas para corroborar a resposta dada por POPPER (1999), uma relacionada ao quadro de oposições da lógica aristotélica, outra relacionada à lógica simbólica da tabela dos valores de verdade e falsidade.

No que diz respeito ao quadro de oposições, observe-o ilustrativamente abaixo: 


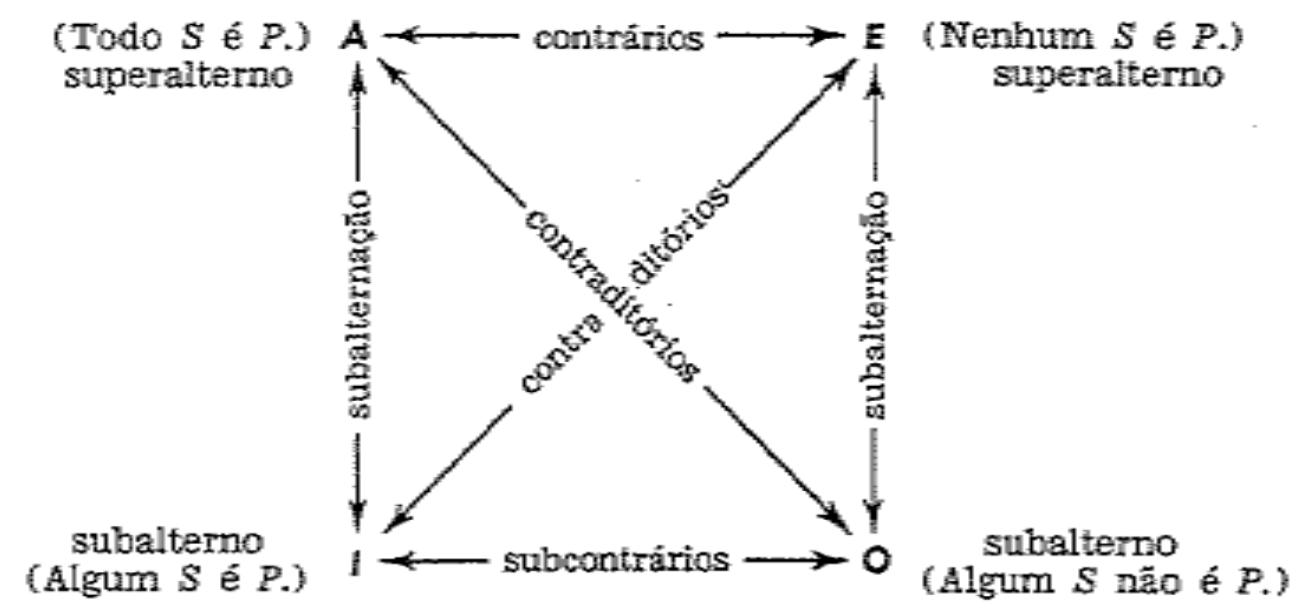

Esse modelo lógico compreende as propriedades de: contrariedade (alternância qualitativa, ou seja, A - E, I - O) e contraditoriedade (alternância quantitativa, i. e., A $\mathrm{O}, \mathrm{E}$ - I); qualidade, que diz respeito à proposição ser ou afirmativa, ou negativa; quantidade, que se refere ao caráter de universalidade ou particularidade das assertivas referidas; subalternação, alternância de diferente quantidade, mas de mesma qualidade.

Além disso, nesse sistema lógico, ocorrem as inferências tidas como imediatas ou diretas, i. e., aquelas que decorrem apenas de uma assertiva. Isso significa que:

1) Se A é verdadeira: E é falsa, I é verdadeira, $O$ é falsa.

2) Se E é verdadeira: A é falsa, I é falsa, O é verdadeira.

3) Se I é verdadeira: E é falsa, A e O são indeterminadas (podem ser falsas ou verdadeiras).

4) Se O é verdadeira: A é falsa, E e I são indeterminadas.

5) Se A é falsa: O é verdadeira, E e I são indeterminadas.

6) Se E é falsa: I é verdadeira, A e O são indeterminadas.

7) Se I é falsa: A é falsa, E é verdadeira, O é verdadeira.

8) Se O é falsa: A é verdadeira, E é falsa, I é verdadeira. 
Veja-se, portanto, que graficamente corresponde a:

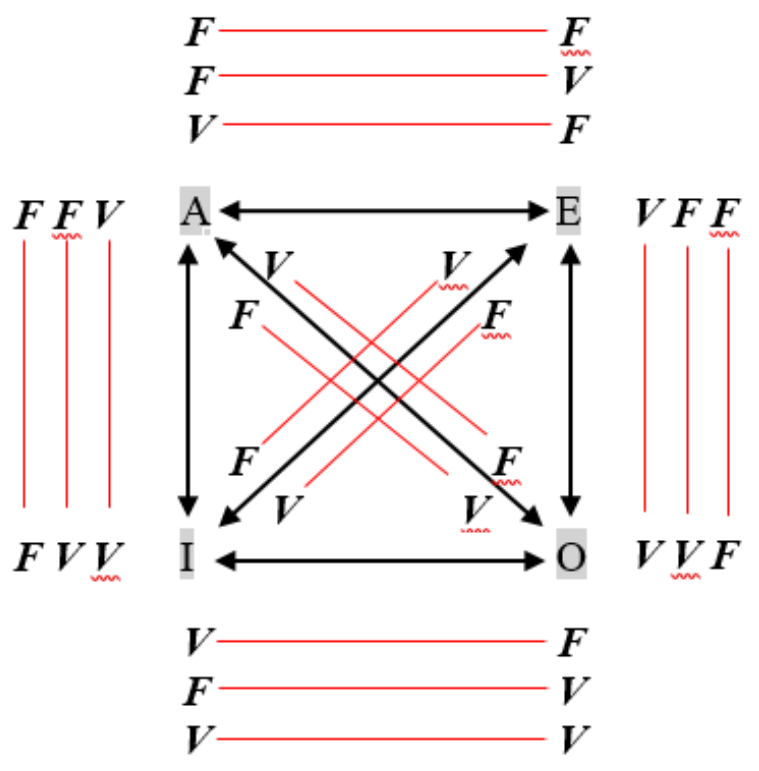

Pelo exposto, basta para perceber que a propriedade de subalternação presume uma relação de implicação entre as proposições A - I e E - O, ou seja, da verdade do primeiro deduz-se a verdade do segundo, não vice-versa, e da falsidade do segundo deduz-se a falsidade do primeiro, não vice-versa.

Portanto, a verdade de uma asserção de teste (proposição particular) possibilita afirmar a verdade ou a falsidade de uma teoria explanativa (proposição universal). Ocorre, pois, uma indeterminação. Isso nos permite dizer apenas e tão somente que as concepções de teorias explanativas inferidas de determinadas asserções de teste são hipóteses, ou conjecturas, ou suposições, nos dizeres de POPPER (1999).

Ademais, em se tratando da lógica simbólica da tabela dos valores de verdade e falsidade, a diversa conclusão seria impossível chegar.

$$
\text { Considere-se o argumento } \frac{\mathrm{q} \rightarrow \mathrm{q}}{\mathrm{p}} \text { em que enunciado composto da primeira }
$$
premissa compreende uma relação condicional relativa na qual o antecedente $p$ equivale a uma proposição particular e o consequente $q$ se refere a uma proposição universal. Essa relação dada se explica pelo pressuposto de que o caráter indutivo pretendido é a decorrência de uma lei universal (ou uma teoria explanativa universal) a partir de um fenômeno particular (ou asserção de teste). 
No que diz respeito à colocação da segunda premissa $q$ e a conclusão $p$, tem-se o indicativo de uma estrutura argumentativa na qual considerando a decorrência de uma proposição universal por uma proposição particular, é adequado pretender que esta mesma assertiva universal, por sua vez, seja capaz de corroborar a própria assertiva particular, daí concluí-la. Contudo, não é o que se constata.

A verificação da validade do raciocínio acima se dá pela coincidência dos valores de verdade da primeira premissa, da segunda premissa e da conclusão verificada na tabela dos valores de verdade para P e Q.

Eis a tabela:

$\begin{array}{cccccccc}\mathbf{P} & \mathbf{Q} & \neg \mathbf{P} & \neg \mathbf{Q} & \mathbf{P} \rightarrow \mathbf{Q} & \neg \mathbf{P} \rightarrow \mathbf{Q} & \mathbf{P} \rightarrow \neg \mathbf{Q} & \neg \mathbf{P} \rightarrow \neg \mathbf{Q} \\ \mathbf{V} & \mathbf{V} & \mathbf{F} & \mathbf{F} & \mathbf{V} & \mathbf{V} & \mathbf{F} & \mathbf{V} \\ \mathbf{V} & \mathbf{F} & \mathbf{F} & \mathbf{V} & \mathbf{F} & \mathbf{V} & \mathbf{V} & \mathbf{V} \\ \mathbf{F} & \mathbf{V} & \mathbf{V} & \mathbf{F} & \mathbf{V} & \mathbf{V} & \mathbf{V} & \mathbf{F} \\ \mathbf{F} & \mathbf{F} & \mathbf{V} & \mathbf{V} & \mathbf{V} & \mathbf{F} & \mathbf{V} & \mathbf{V} \\ & & & & & & & \\ \mathbf{P} & \mathbf{Q} & \neg \mathbf{P} & \neg \mathbf{Q} & \neg(\mathbf{P} \rightarrow \mathbf{Q}) & \neg(\neg \mathbf{P} \rightarrow \mathbf{Q}) & \neg(\mathbf{P} \rightarrow \neg \mathbf{Q}) & \neg(\neg \mathbf{P} \rightarrow \neg \mathbf{Q}) \\ \mathbf{V} & \mathbf{V} & \mathbf{F} & \mathbf{F} & \mathbf{F} & \mathbf{F} & \mathbf{V} & \mathbf{F} \\ \mathbf{V} & \mathbf{F} & \mathbf{F} & \mathbf{V} & \mathbf{V} & \mathbf{F} & \mathbf{F} & \mathbf{F} \\ \mathbf{F} & \mathbf{V} & \mathbf{V} & \mathbf{F} & \mathbf{F} & \mathbf{F} & \mathbf{F} & \mathbf{F} \\ \mathbf{F} & \mathbf{F} & \mathbf{V} & \mathbf{V} & \mathbf{F} & \mathbf{V} & \mathbf{F} & \end{array}$

Observe-se que a conclusão alterna entre os valores de verdade falsidade, ou seja, o que se conclui é duvidoso. Portanto, se não há certeza quanto à asserção de teste, como justificar o valor de verdade da teoria explanativa universal já que esta não se aplica a todos os seus casos particulares? É apenas possível admitir, com isso, que talvez seja verdadeira a lei universal em questão, ou talvez seja falsa.

Em conclusão à reformulação do problema da indução, POPPER (1999) indica uma situação na qual diante de inúmeras teorias explanativas se tenha que escolher uma. A terceira formulação feita pelo autor é:

$\mathrm{L}_{3}$ - pode uma preferência, com respeito à verdade ou à falsidade, por algumas teorias universais em concorrência com outras ser alguma vez justificada por tais "razões empíricas"?

À luz de minha resposta $\mathrm{a}_{2}$ a resposta $\mathrm{a} \mathrm{L}_{3}$ torna-se óbvia: sim; às vezes pode, se tivermos sorte. Pois pode acontecer que nossas asserções de teste refutem algumas - mas não todas - teorias concorrentes; e como estamos procurando uma teoria verdadeira, preferiremos aquelas cuja falsidade não foi estabelecida. (POPPER, 1999, p. 19).

O que Popper conclui é que a solução para o problema da indução, ao contrário do que propunham os indutivistas que defendiam o verificacionismo, é a constante 
refutação ou tentativa de falsear a teoria explanativa, indicando situações em que seja suscetível de falhas.

Assim se expressa o autor:

\begin{abstract}
A diferença fundamental entre meu processo e o processo para o qual apresentei há muito tempo a etiqueta de "indutivista" está em que dou ênfase a argumentos negativos, tais como exemplos negativos ou contra-exemplos, refutações e tentativas de refutações - em suma, crítica - ao passo que o indutivista dá ênfase a "exemplos positivos", dos quais extrai "inferências não demonstrativas, esperando que assegurem a "fidedignidade" das conclusões dessas inferências. A meu ver, tudo quanto pode ser possivelmente "positivo" em nosso conhecimento científico só é positivo até onde certas teorias, em certos momentos do tempo, sejam preferidas a outras, à luz de nossa discussão crítica, que consiste de refutações tentadas, inclusive testes empíricos. Assim, mesmo o que pode ser chamado "positivo" só o é com respeito a métodos negativos. (POPPER, 1999, p. 30-31).
\end{abstract}

O esforço argumentativo de Popper se pauta na negação de toda e qualquer certeza ou tentativa de justificação do pensamento científico porquanto indutivo. Afinal, numa perspectiva objetiva do conhecimento, as teorias empíricas não são absolutas. Elas subsistem permeadas de plausibilidade não porque são em si mesmas justificadas, mas sim em razão de até o respectivo momento inexistirem contrapontos refutatórios.

Enquanto as crenças e o senso comum se inclinam às verdades inquebrantáveis, a racionalidade indutiva só permite vislumbrar dúvidas ou incertezas. Ao conhecimento objetivo cabe a incômoda afirmação de que da natureza nada se sabe por certo, apenas se conjectura.

\title{
2 TÓPICA
}

Define-se a Tópica sob o prisma filosófico como dialética, o que encerra o provável. Veja-se:

(do gr. topos, lugar) A Tópica ou Tratado dos tópicos é um dos tratados que compõem o *Organon, a lógica aristotélica. Os oito livros do Tratado dos tópicos têm como tema a *dialética, considerada como as regras silogísticas que se aplicam a proposições prováveis, como as da opinião comum (endoxa) [...] (JAPIASSÚ, 1990, p. 268). 
A ciência jurídica a incorpora numa perspectiva de teoria da argumentação sem, contudo, afastar sua essencialidade do incerto, pois os topoi (lugares comuns ou opiniões norteadoras) levam a conclusões apenas possíveis. Cita-se:

\begin{abstract}
tópica - Técnica de resolução de problemas jurídicos baseada em "topoi", ou tópicos. tópico(s) ("topos", "topoi") - 1. Lugar. Lugar-comum. 2. Certos pontos ("chefs") gerais, a que se ligam os argumentos ("preuves") que utilizamos (lpr). 3. Fórmula de procura, perceptível no curso da discussão, que orienta a argumentação (tsf). 4. Ponto de vista utilizável em múltiplas instâncias, com validade geral, que serve para a ponderação dos prós e contras das opiniões e nos pode conduzir à verdade (kl) (CUNHA, 2011, p. 284).
\end{abstract}

Em suma, a Tópica é essencialmente indutiva. É demarcada pela dialética e retórica aristotélicas. É desprendida das verdades primeiras. É um modelo argumentativo pautado no pensamento problemático cujas premissas norteadoras são as endoxa.

\title{
2.1 Tópica e Jurisprudência em Theodor Viehweg
}

VIEHWEG (1979) em Tópica e Jurisprudência concebe a Tópica como uma técnica do pensamento problemática, diferentemente da concepção aristotélica que a definia como um método. Segundo o autor, considerando que o Direito se pauta essencialmente pela busca em resolver problemas práticos, então o raciocínio jurídico deve possuir um caráter tópico.

Nesse sentido, VIEHWEG (1979) inadmite o pensamento jurídico pautado num exclusivo modelo lógico-dedutivo e o admite a partir de uma natureza Tópica. "A tópica é uma técnica de pensar por problemas, desenvolvida pela retórica. Ela se desdobra numa contextura cultural que se distingue claramente nas menores particularidades de outra de tipo sistemático dedutivo.” (VIEHWEG, 1979, p. 17).

Dessa forma, a Tópica delineada "como a forma segundo a qual deveria ser pensada a realidade jurídica, a ser empregada no lugar do modo lógico-dedutivo, em voga no século XIX, considerada a jurisprudência, nesse período, 'mistificatoria'." (ZANDONADE, 1999, p. 2) é apresentada pelo referido autor com base nos referenciais teóricos Aristotélico e Ciceroniano, ambos, conciliados de acordo com o entendimento de Gian Battista Vico em sua obra de 1708 intitulada De Nostri Temporis Studiorum Ratione.

O pensador VICO, citado por VIEHWEG (1979), mescla o modo de pensar “antigo", pautado na dialética ou Tópica Aristotélica, bem como no discurso pragmático 
da Tópica de Cícero, com o modo de pensar "novo" qualificado pelo método críticocartesiano. Assim afirma:

Tudo isso, porém, segundo Vico, pode ser evitado pelo antigo método retórico e, especialmente, pela sua peça medular, a tópica retórica. Esta proporciona sabedoria, desperta a fantasia e a memória e ensina como considerar um estado de coisas de ângulos diversos, isto é, como descobrir uma trama de pontos de vista. Deve-se intercalar, diz Vico, o antigo modo de pensar tópico com o novo, pois este sem aquele na verdade não se efetiva. (VIEHWEG, 1979, p. 21).

Na perspectiva de ATIENZA (2006), Viehweg sistematiza a Tópica da seguinte maneira:

[...] a tópica é, do ponto de vista de seu objeto, uma técnica do pensamento problemático; por outro lado, do ponto de vista do instrumento com que opera, o que se torna central é a noção de topos ou lugar-comum; finalmente, do ponto de vista do tipo de atividade, a tópica é uma busca e exame de premissas; o que a caracteriza é ser um modo de pensar no qual a ênfase recai nas premissas, e não nas conclusões. (ATIENZA, 2006, p. 49).

Assim, na ótica do seu objeto, a Tópica é um auxílio para a solução de problemas difíceis, ditos aporias. Sua qualificação, portanto, é um modo de pensar aporético em contraposição ao modo de pensar sistemático (HARTMANN apud ATIENZA, 2006).

A definição de problema proposta por VIEHWEG (1979) é um contraponto ao que se entende por sistema. Veja-se:

Toda questão que aparentemente permite mais de uma resposta e que sempre exige um entendimento preliminar, de acordo com o qual assume o aspecto de questão que é preciso considerar com seriedade e para a qual é preciso buscar uma única resposta como solução. Isto se desenvolve abreviadamente do seguinte modo: o problema, através de uma reformulação adequada, é trazido para dentro de um conjunto de deduções, previamente dado, mais ou menos explícito e mais ou menos abrangente, a partir do qual se infere uma resposta. Se a este conjunto de deduções chamamos sistema, então podemos dizer, de um modo mais breve, que, para encontrar uma solução, problema se ordena dentro de um sistema. (VIEHWEG, 1979, p. 50).

Contudo, ATIENZA adverte para a falta de clareza em tal distinção e propõe uma leitura pauta no enfoque que se dá ao problema ou ao sistema. Em sua percepção,

todo pensamento - toda disciplina - surge a partir de problemas e dá lugar a algum tipo de sistema, mas a ênfase pode recair em um ou outro elemento. Se a ênfase é posta no sistema, então este realiza uma seleção dos problemas e, assim, os que não recaem sob ele são afastados e ficam simplesmente sem ser 
resolvidos. Se, pelo contrário, a ênfase é posta no problema, então se trata de buscar um sistema que ajude a encontrar a solução; o problema leva assim a uma seleção de sistemas e em geral a uma pluralidade de sistemas; aqui se trataria, portanto, de algo assim como um sistema aberto no qual o ponto de vista não é adotado de antemão. (ATIENZA, 2004, p. 50).

Posto que o Direito se presta à solução de litígios concretos, é preferível que seja dada ênfase ao pensamento problemático. Nesse caso, não se trata de negar o pensamento sistemático, mas apenas a dificuldade de se conceber primeiramente um sistema na tentativa de resolver a aporia (AVILA, 2013a).

Assim, reiterando a máxima alusiva à Tópica proposta por VIEHWEG (1979), qual seja, "técnica do pensamento problemático", conclui-se que os topoi, do grego topos, lugares comuns da opinião, dos pontos de vista acerca de um assunto, são vinculados ao problema. Trata-se da busca das endoxa capazes de direcionar a aporia em voga de modo a estabelecer uma solução plausível, provável, pertinente ao caso em comento. Ou seja,

[...] não se cuida de que sejam os tópicos construções isoladas ou meramente teóricas, nem, por outro lado, simples dados ou fenômenos. São, em lugar disso, fórmulas de procura de soluções, destinadas a orientar uma argumentação que visa a oferecer um resultado à questão problemática, mas construídas de acordo com as peculiaridades de cada situação concreta, que lhes definirá o conteúdo. (ZANDONADE, 1999, p. 5)

Em relação ao processo operacional da Tópica, ganha relevo os topoi. Esse arranjo se constitui de inúmeras endoxa amplamente aceitas e aplicáveis ou a qualquer tema que se discuti problematicamente ou a uma questão delimitada.

Nessa ótica, o agrupamento prefixado dos topoi a serem utilizados se presta sempre a solução de um problema e dado o dinamismo do direito esse arranjo é flexível. Sempre que for necessário, novos pontos de vista são adotados de acordo com a interpretação jurisdicional ou legislação vigente no momento. Assim, a partir do pensamento jurídico,

[...] pensar topicamente significa manter princípios, conceitos, postulados, com um caráter problemático, na medida em que jamais perdem sua qualidade de tentativa. Como tentativa, as figuras doutrinárias do Direito são abertas, delimitadas sem maior rigor lógico, assumindo significações em função dos problemas a resolver, constituindo verdadeira 'fórmulas de procura' de solução de conflito. Noções-chaves como 'interesse público', 'vontade contratual', 'autonomia da vontade', bem como princípios básicos como 'não tirar proveito da própria ilicitude', 'dar a cada um o que é seu', 'in dubio pro reo' guardam um sentido vago que se determina em função de problemas como a relação entre sociedade e indivíduo, proteção do indivíduo em face do Estado, do indivíduo de boa-fé, distribuição dos bens numa situação de escassez etc., 
problemas estes que se reduzem, de certo modo, a uma aporia nuclear, isto é, a uma questão sempre posta e renovadamente discutida e que anima toda a jurisprudência: a aporia da justiça. (VIEHWEG, 1979, p. 3-4)

Ademais, no que diz respeito à Tópica como uma atividade, sua característica marcante é a de ser uma arte da invenção (ars inveniendi), uma busca contínua de premissas. Diferentemente ocorre com o modelo lógico-dedutível ou demonstrativo, pois neste há a utilização de premissas apriorísticas, axiomáticas e por isso per se verdadeiras, a fim de se chegar às inferências válidas, já naquele, a pretensão é alcançar premissas aptas a se correlacionarem com o problema em discussão.

Viehweg concebe como contrários o modelo dedutivo de raciocínio jurídico e a Tópica. Para tanto, o jusfilósofo afirma que "quando se logra estabelecer um sistema dedutivo, a que toda ciência do ponto de vista lógico, deve aspirar, a tópica deve ser abandonada." (VIEHWEG, 1979, p. 43).

As premissas almejadas pela atividade tópica são legitimadas pela razoabilidade da opinião comumente difundida e não, como ocorre no método dedutivo, demonstradas ou fundamentadas.

O exercício tópico é, em certa medida, dialético e retórico numa concepção aristotélica, portando, contrário ao modelo dedutivo e apodíctico, pois

os tópicos são concebidos como premissas compartilhadas que, não sendo absolutamente verdadeiras e evidentes, possuem uma carga de probabilidade que os torna instrumentos adequados para um convencimento racional sobre a melhor solução para uma situação problemática. (AVILA, 2013a, p. 77).

Ademais, VIEHWEG (1979) encontra no Direito Romano (jus civile) e no Direito Medieval (mos italicus) notórios exemplos de aplicação do raciocínio tópico no âmbito da racionalidade jurídica. Pode-se justificar tal afirmação pelo fato de que:

[...] a jurisprudência na Idade Antiga e na Idade Média davam ao problema concreto uma colocação de preeminência, representando os textos normativos nada mais do que autênticos "catálogos" ou "repertórios" de argumentos, escolhidos em razão da força da autoridade de seu reconhecimento, mas reunidos sem qualquer pretensão sistemática, eis que funcionalmente a serviço de uma discussão de problemas. (ZANDONADE, 1999, p. 8).

Portando, o uso de decisões judiciais referentes a casos anteriores ao que se discute no presente, bem como as inúmeras citações dos “entendimentos doutrinários" acerca de 
um tema servem como premissas ou topoi selecionados para se buscar uma solução ao problema jurídico em voga. Trata-se, não raro, da preferência por uma seleção do melhor juízo ou das melhores opiniões acerca de um tema de Direito a fim de resolver o problema em discussão em detrimento de uma argumentação dedutiva na qual se demonstra a validade lógica das teses resolutivas inferidas das premissas postas. É mister atentar para ideia de que o exercício tópico no raciocínio jurídico tende a uma retórica de autoridade, isto é, o argumento desenvolvido através de citações jurisdicionais e/ou doutrinárias possui validade em razão da pessoa ou órgão que profere os topoi selecionados e não em função da sua estrutura lógico-linguística e das percepções fáticas.

O caráter tópico do raciocínio jurídico, portanto, caracteriza-se pelo uso recorrente de precedentes ou das referências às opiniões dos juristas. Esses elementos constituem premissas elencadas e direcionadas à solução da questão jurídica em discussão.

Em relação à jurisprudência, o exercício da Tópica é uma referência de pensamento em que ao se observar vários casos se torna possível identificar um padrão útil no julgamento de vários outros casos posteriores. Nesse sentido, o precedente na Tópica serve como uma solução padronizada e predefinida para se julgar o caso concreto presente (AVILA, 2013a).

Assim, o que vale é traçar um parâmetro normativo após serem julgados ou observados inúmeros casos de modo que esse mesmo padrão (solução) sirva para julgar todo e qualquer caso futuro.

Adota-se, com isso, uma perspectiva essencialmente retórica e dialética em razão do juízo de probabilidade das conclusões propostas e dos vários topos (ou lugarescomuns) que servem como premissas úteis na elaboração de uma solução verossímil, pois, marcadamente indutivo.

No que diz respeito à endoxa, a simples citação de textos escritos por um especialista na área ou jurista qualifica o teor tópica do raciocínio. Deveras, ante o problema acerca do conceito de determinado instituto ou expressão jurídica, a reprodução da opinião de um douto em sua área por si só evidencia a ideia de que dizer a essência daquilo que se busca entender equivale a apontar o que já foi dito por outrem.

De tudo exposto, conclui-se que a Tópica, embora ATIENZA (2004) não a considere especificamente uma teoria jurídica de argumentação com próprio modus de racionalidade, trata-se, como insiste VIEHWEG (1979), de uma técnica apartada do Direito, mas a este aplicada com primordial intento de resolver os problemas que lhe são 
afetos. E sua principal característica, conforme metodologicamente delimitado pela presente pesquisa, diz respeito à sua essencialidade indutiva .

\subsection{O caráter indutivo da Tópica em contraponto ao problema da indução}

A Tópica enquanto técnica do pensamento problemático (VIEHWEG, 1979) nos limites semânticos anteriormente traçados possui uma essencialidade indutiva, podendo, com isso, da maneira como foi concebida por Aristóteles, repensada por Cícero, conciliada em Vico e metodologicamente proposta por Theodor Viehweg no âmbito do raciocínio jurídico, ser contraposta ao problema da indução.

É mister destacar que a indução definida como um processo de inferência qualificado pelo grau de probabilidade da conclusão decorrente das premissas, conforme dito anteriormente, demonstra-se estritamente essencial às ciências da natureza, mas no campo das ciências humanas pode ser dispensada ou, caso seja adotada no processo argumentativo, deve-se ter claro o seu caráter defectivo.

O método indutivo constitui a base do modelo de pensamento das ciências empíricas, porquanto é o único viável, conforme apontado por POPPER (1999). Não obstante isso, o mencionado autor destaca os limites de tal tipo de raciocínio, pois

\footnotetext{
De um ponto de vista racional, não podemos "confiar" em teoria alguma, pois nunca se mostrou, nem se pode mostrar, que qualquer teoria é verdadeira.

[...] Podemos preferir, entretanto, como base de ação, a teoria mais bem testada.

Em outras palavras, não há "confiança absoluta"; desde, porém, que tenhamos de escolher, será "racional" escolher a teoria mais bem testada. Será "racional" no sentido mais óbvio que conheço dessa palavra: a teoria mais bem testada é aquela que, à luz de nossa discussão crítica, parece ser a melhor até agora, e não conheço coisa mais "racional" do que uma discussão crítica bem conduzida. (POPPER, 1999, p. 32).
}

Assim, qualquer teoria ou conclusão pautado no raciocínio indutivo não pode ser considerada verdadeira. Apesar disso, para as ciências da natureza referida limitação é afastada por meio da "testabilidade" ou, nos termos de POPPER (1999), "falseabilidade".

Todavia, no campo das ciências humanísticas em que se admite um sistema lógico dedutivo de racionalidade, o método indutivo se utilizado deve sê-lo com a clareza de que é defeituoso, i. e., de que é um modelo racional distanciado da verdade e próximo da 
persuasão engendrada pelo maior ou menor grau de probabilidade das inferências elaboradas.

De acordo com a explanação feita, a indução compreendida nos aspectos do argumento por analogia, a partir das relações causais na qualidade de modelo explicativo e justificador dos fenômenos observáveis, no âmbito do raciocínio por generalização e, por fim, nos limites do problema da indução apontado por POPPER (1999), essa definida indução que é uma das características essenciais do conceito de Tópica atrai para esta (Tópica) sua qualidade defectiva ou problemática (da indução).

Assim, a contraposição entre Tópica e indução pressupõe, primeiro, o fato de que esta compõe os limites semânticos daquela que, por sua vez, e em segundo, é afetada pelos defeitos da própria indução. Dito de outro modo, aplicar a Tópica como técnica de raciocínio a fim de se solucionar problemas no âmbito do Direito ou da discussão jurídica requer, de antemão, aceitar a indução como modelo racional de fundamentação e, $a$ posteriori, evidenciar o indissolúvel problema da indução no âmbito do raciocínio jurídico haja vista ser possível aduzir tanto a verdade, quanto a falsidade das inferências desenvolvidas.

Não obstante tais conclusões acerca das "falhas" do argumento indutivo, é possível sustentar que a argumentação jurídica não afasta a Tópica por completo, haja vista que

o raciocínio, principalmente o raciocínio jurídico, não é designado somente por um silogismo ou lógica formal, de cunho estritamente dedutivo. Trata-se antes de tudo e dada a unidade do diverso, de uma sucessão de discursos apodíticos, dialéticos, retóricos e poéticos, que se traduz [...] para uma aproximação em relação a verdade. (AVILA, 2013a, p. 113).

Não apenas o interesse acadêmico pela temática da Tópica Jurídica evidencia seu uso na argumentação do Direito, mas também as inúmeras produções doutrinárias ou jurisprudenciais em que são evidenciados traços marcantes desse tipo de raciocínio.

Apesar da Tópica fazer parte da sistemática da argumentação jurídica que objetiva desenvolver um discurso direcionado à verdade das proposições fáticas e estritamente jurídicas, seu uso não é adequado em quaisquer áreas do Direito.

Assim se expressa MADEIRA (2012):

discurso processual deve observar normas (regras e princípios) como: a) proibição do solipsismo decisional; b) formalização argumentativa; c) objetividade argumentativa; d) correlação lógica dos argumentos; e) 
observância de um procedimento (conceito fazzalariano); f) observância dos princípios da reserva legal e supremacia da Constituição; g) observância do devido processo, isso tudo, somente para citar alguns aspectos que, desde Aristóteles até Viehweg, não são observados pela tópica jurídica, inviabilizando a utilização desta, ao menos, nos moldes até hoje conhecidos. (MADEIRA, 2012, p. 30).

Portanto, pode-se afirmar que a Tópica e o Processo são incompatíveis, pois a sistematização processual compreende a observância de diversos princípios norteadores que, em tese, não são afetos a este tipo argumentativo.

\section{CONCLUSÃO}

Em vista dos argumentos apresentados ao longo desta pesquisa, pode-se asseverar que o discurso dialético ou raciocínio indutivo é marcado pela incerteza, probabilidade e verossimilhança das suas conclusões.

O argumento por indução se pauta não numa implicação de necessariedade com as premissas postas, mas sim numa perspectiva de possibilidade já que a conclusão em que se chega pode ser ou verdadeira, ou falsa e, portanto, duvidosa, incerta.

À vista disso, argumentou-se que a Tópica é essencialmente indutiva porquanto se trata de um discurso dialético e retórico.

O raciocínio genuinamente tópico por ser um processo de busca das topoi objetivando a solução de aporias não se atém à verdade ou demonstrabilidade das premissas com as quais trata, mas as aceita como possivelmente aptas a solucionarem o problema em debate. Razão disso, as endoxa, opiniões largamente aceitas de juristas, princípios ou lugares comuns das razões para se decidir, e os referenciais jurisprudenciais de aplicação do Direito ao constituírem, primordialmente, as proposições antecedentes são consideradas por si mesmas e não a partir de uma verdade primária.

Dessa forma, à questão se uma argumentação jurídica de cunho tópico pode ser justificada, a resposta é logicamente não. Há de se considerar a dúvida se o foco for a verdade. Porém, é bem possível fazer dela um meio de persuasão implicado com a diversidade do raciocínio jurídico.

Assim, há alguma razoabilidade em pensar que a Tópica não deva ser por completo afastada da argumentação jurídica em razão do seu aspecto indutivista, embora não seja adequada em toda e qualquer área do Direito. 
Portanto, esse conjunto de ideias apresentadas viabiliza a conclusão de que a Tópica por ser essencialmente indutiva está sujeita ao caráter defeituoso deste tipo de raciocínio sem que por isso seja inviabilizada e afastada totalmente do campo do Direito. 


\section{REFERÊNCIAS}

ALEXY, Robert. Teoria da argumentação jurídica: a teoria do discurso racional como teoria da fundamentação jurídica. 3. ed. Rio de Janeiro: Forense, 2011. XII, 350 p.

ARISTÓTELES. Organon: categorias da interpretação, analíticos anteriores, analíticos posteriores, tópicos, refutações sofísticas. Tradução de Edson Bini. 2. ed. rev. Bauru, SP: Edipro, 2010. 608 p. (Série Clássicos Edipro).

ATIENZA, Manuel. As razões do direito: teorias da argumentação jurídica. 3. ed. São Paulo: Landy, 2006. 238 p.

ÁVILA, Luiz Augusto Lima de. A natureza do conhecimento jurídico entre ciência e prudência: a lógica abdutiva e a fundamentação do direito em Theodor Viehweg. Belo Horizonte: FUMARC, 2013. 122 p.

ÁVILA, Luiz Augusto Lima de. Lógica jurídica: uma análise linguística das regras de predicação e intermediação de conceitos jurídicos. Belo Horizonte: Arraes, 2013. 258 p.

COPI, Irving M. Introdução à lógica. 2. ed. São Paulo: Mestre Jou, 1978. 488 p.

CUNHA, Sérgio Sérvulo da. Dicionário compacto do direito. 10. São Paulo: Saraiva, 2011.

HOUAISS, Antônio; VILLAR, Mauro; FRANCO, Francisco Manoel de Mello.

Minidicionário Houaiss da língua portuguesa. 4. ed. rev. e aumentada. Rio de Janeiro: Objetiva, 2010.

HUME, David. Investigação acerca do entendimento humano: Ensaios morais, políticos e literários. São Paulo: Nova Cultural, 1996. 352p. (Os pensadores).

Livro III: Da Indução, capítulo II, p. 168-74.

JAPIASSÚ, Hilton. Dicionário básico de filosofia. Rio de Janeiro: Zahar, 1990.

LAUX, Evelise Rosane Treptow. O problema da indução: de Hume a Popper A confiabilidade da ciência na visão de Hume e Popper, tendo por base a questão da indução. Controvérsia. São Leopoldo, v. 8, n. 1, 2012.

MADEIRA, Dhenis Cruz. Tópica e processo. 2012. 551 f. Tese (Doutorado) Pontifícia Universidade Católica de Minas Gerais, Programa de Pós-Graduação em Direito.

MILL, John Stuart. Sistema de lógica Dedutiva e Indutiva, seleção traduzida por J. M. Coelho, in Os Pensadores, 2a ed. Abril Cultura, São Paulo, 1979, p. 81-257.

MORA, José Ferrater. Dicionário de filosofia. Tradução de Roberto Leal Ferreira, Álvaro Cabral. 4. ed. São Paulo: Martins Fontes, 2001. 
POPPER, Karl Raimund Sir. Conhecimento objetivo: uma abordagem evolucionária. Belo Horizonte: Itatiaia, 1999. 394 p. (Coleção Espírito do nosso tempo; 13)

REALE, Giovanni; ANTISERI, Dario. História da filosofia: filosofia pagã antiga. 10. ed. v. 1. São Paulo: Paulus, 2007. XVIII, 385 p.

SAGAN, Carl. Os dragões do Eden: especulações sobre a evolução da inteligência humana. 5. ed. Rio de Janeiro: F. Alves, 1987. 195p.

TROSTER, Tomás Roberto. Indução e ciência em Aristóteles. 2015. 182 f. Tese (Doutorado) - Faculdade de Filosofia Letras e Ciências Humanas da Universidade de São Paulo. Departamento de Filosofia.

VIEHWEG, Theodor. Tópica e jurisprudência. Brasília: Imprensa Nacional, 1979 155p. (Pensamento jurídico contemporâneo).

ZANDONATE, Adriana. A tópica e a interpretação da norma constitucional. Revista de Direito Constitucional e Internacional, [s. l.], vol. 26, p. 210-226, 1999, versão online. Revista dos Tribunais Thomson Reuters. 